ETHNICITY

\title{
Diabetes and ethnic minorities
}

\author{
J Oldroyd, M Banerjee, A Heald, K Cruickshank
}

Postgrad Med J 2005;81:486-490. doi: 10.1136/pgmj.2004.029124

The global prevalence of diabetes for all age groups is estimated to be $2.8 \%$. Type 2 diabetes accounts for at least $90 \%$ of diabetes worldwide. Diabetes incidence, prevalence, and disease progression varies by ethnic group. This review highlights unique aspects of the risk of developing diabetes, its overwhelming vascular complications, and their management mainly using data among South Asians and African-Caribbeans in the UK but also using non-UK data. It is concluded that although the origin of the ethnic differences in incidence need further clarification, many factors should be amenable to prevention and treatment in all ethnic groups worldwide.

See end of article for authors' affiliations

.....................

Correspondence to: Dr J Oldroyd, University Department of Medicine, Manchester Royal Infirmary, Oxford Road, Manchester M13 9WL, UK; john.oldroyd@man. ac.uk

Submitted

26 September 2004

Accepted

18 December 2004
$\mathrm{T}$ he term ethnicity refers to common cultural traditions, geography, ancestry, religion, and history. The term comes from the Greek word "ethnos", which means "nation" or "peo-

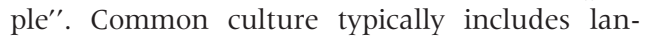
guage, religion, and diet. Ethnicity typically also refers to culture within a culture-that is, a group of people with a common or shared identity, living within a larger, mainstream group.

Three ways to establish ethnicity are:

- Parental or preferably grandparental origin

- Self identity-permitting people to assert their own identity, which is in keeping with the patient centred approach of the NHS

- Appearance-although this is now discredited as it has poor reproducibility and serves a political not a scientific role.

The population in Great Britain is multiethnic and is very dynamic as exemplified by the growth of the minority ethnic population by $53 \%$, from 3.0 million in 1991 to 4.6 million in 2001 (census 2001). Half of the total minority ethnic population was South Asian (Indian, Pakistani, Bangladeshi, or other Asian origin), $25 \%$ African-Caribbean, and $15 \%$ of mixed origin.

The changing ethnic composition of developing countries and the progressive population enrichment with ethnic groups who are at high risk of diabetes such as South Asians, Caribbeans, and West Africans highlights the need to be aware of the variations in disease manifestations and management in these population groups.

\section{INCIDENCE AND PREVALENCE OF DIABETES ACCORDING TO ETHNIC GROUPS \\ Worldwide}

The prevalence of diabetes (all forms) was recently reviewed and the worldwide prevalence for all age groups was estimated to be $2.8 \% .^{1}$ The total number of people with diabetes is projected to rise from 171 million in 2000 to 366 million in 2030, largely because of an increase in the proportion of people over 65 years of age. ${ }^{1}$ The regions with the greatest potential increases are Asia and Africa, where diabetes rates are predicted to rise to two or three times those experienced today. The "top three" countries with the maximum prevalence of diabetes are India, China, and the USA. Large increases in prevalence are also expected, mostly in countries such as Bangladesh, Brazil, Indonesia, Japan, and Pakistan.

\section{Type 1 diabetes}

Type 1 diabetes is less prevalent than type 2 diabetes accounting for up to $10 \%$ of all cases. This form of diabetes has been noted for its peak incidence at childhood and adolescence, ${ }^{2}$ although the demographic pattern is changing in view of the emergence of type 2 diabetes among adolescents. ${ }^{3}$

The incidence of type 1 diabetes is highest in the temperate regions (about 30 to 35 cases per 100000 children per year) and declines progressively towards the equator. High prevalence is noted within populations from these regions even when distributed in other parts of the world. A trend of a small gradual increase in incidence of type 1 diabetes has been noted globally, although the underlying causes for this secular trend are not clear. ${ }^{245}$

Type 1 diabetes is associated to other autoimmune conditions as hypothyroidism, hypoadrenalism, pernicious anaemia, autoimmune hepatitis, and rheumatoid arthritis in about 5\%$15 \%$ of cases. ${ }^{6}$ Ethnic differences between the incidences of these autoimmune conditions among people with type 1 diabetes have not been reported.

\section{Type 2 diabetes}

Type 2 diabetes accounts for at least $90 \%$ of diabetes worldwide. ${ }^{7}$ The prevalence among the white European population varies from 2\% overall to $10 \%$ in age group above 70 years. It is much more common in the ethnic minorities groups residing in the developed countries; South Asian and African-Caribbean groups in the UK in particular have a high prevalence. ${ }^{8}$

Type 2 diabetes is most commonly diagnosed in those over 40 years of age, however, much younger people are now presenting with type 2 diabetes, after the rapid rise in obesity. ${ }^{910}$ 
The prevalence of type 2 diabetes ranges from less than $2 \%$ in China to $50 \%$ among the Pima Indians. ${ }^{11}$ Prevalence is rising rapidly globally reflecting the pandemic of obesity that is spreading throughout the world. The American-Indians are the best examples of this process, but it is also being found in every ethnic group in the world. ${ }^{12}$

\section{MODY}

Maturity onset diabetes of the young (MODY) is a heterogeneous group of autosomal dominantly inherited, young onset $\beta$ cell disorders. In white UK children the prevalence of MODY is similar to the prevalence of type 2 diabetes, and has been found to be extremely low in other ethnic groups where type 2 diabetes is prevalent. ${ }^{13} 14$

Incidence and prevalence of type 2 diabetes in the UK Table 2 presents age and sex standardised prevalence rates of type 2 diabetes according to ethnic group in the UK. ${ }^{15}$ The prevalence of adult type 2 diabetes is about three to five times greater in African-Caribbean and South Asian people respectively compared with the white European population. The prevalence of diabetes is not substantially different among Chinese compared with the general UK population.

\section{Risk factors for the development of type 2 diabetes}

There is evidence that certain ethnic groups have a predisposition to type 2 diabetes in the presence of the same risk factors. For example, among adult South Asians there are higher rates of obesity, central fat distribution, and resulting insulin resistance than in white populations. ${ }^{16}{ }^{17}$ Nutritional factors (reduced intake of vitamin B12 and folate, because of prolonged cooking of vegetables ${ }^{18}$ ) and lower levels of habitual physical activity ${ }^{19}$ also play their part in increasing the risk of diabetes in these population groups. Adverse risks may emerge even in childhood as shown in South Asian children in the UK. ${ }^{20}$

\section{Developmental origins of diabetes by ethnic group}

The developmental origins hypothesis suggests that growth restriction in utero in addition to catch up growth in early life give rise to metabolic programming that results in a greater risk of diabetes in adulthood. This has been found in white Europeans in Finland ${ }^{21}$ and the UK. ${ }^{22-24}$ As noted, there is some evidence for a greater number of risk factors in South Asian children compared with European children in the UK. In a 1994 cross sectional study in 8-11 year olds, central adiposity and mean insulin concentration was higher in South Asians (percentage difference (95\% CI) was 53 (14 to 106) after fasting and 54 (19 to 99) after glucose load)

Table 1 Ethnic distribution in 2001 UK census

\begin{tabular}{|c|c|c|c|}
\hline & \multicolumn{2}{|c|}{ Total population } & \multirow{2}{*}{$\begin{array}{l}\text { Ethnic } \\
\text { population \% }\end{array}$} \\
\hline & Count & $\%$ & \\
\hline White & 54153898 & 92.1 & - \\
\hline Mixed & 677117 & 1.2 & 14.6 \\
\hline \multicolumn{4}{|l|}{ Asian } \\
\hline Indian & 1053411 & 1.8 & 22.7 \\
\hline Pakistani & 747285 & 1.3 & 16.1 \\
\hline Bangladeshi & 283063 & 0.5 & 6.1 \\
\hline Others & 247664 & 0.4 & 5.3 \\
\hline \multicolumn{4}{|l|}{ Black } \\
\hline Caribbean & 565876 & 1.0 & 12.2 \\
\hline African & 485277 & 0.8 & 10.5 \\
\hline Other & 97585 & 0.2 & 2.1 \\
\hline Chinese & 247043 & 0.4 & 5.3 \\
\hline Others & 230975 & 0.3 & 5.1 \\
\hline All minority ethnic population & 4635296 & 7.9 & 100 \\
\hline$\%$ Of whole population & 58789194 & 100 & 7.9 \\
\hline
\end{tabular}

although glucose concentrations were similar, suggesting a higher risk of diabetes evident even in childhood in these ethnic groups. ${ }^{2}$ Furthermore, Yajnik's work shows that babies born in Pune, India had a "thin-fat" phenotype with higher proportional central fat (despite lower birth dimensions) and higher cord blood insulin concentrations, than babies born in the UK. ${ }^{25}$

\section{Incidence and prevalence of diabetes related conditions according to ethnic groups Obesity}

Obesity is an important contributing factor to increased insulin concentrations and decreased insulin sensitivity ${ }^{26}$ almost certainly attributable to increased portal blood free fatty acids from visceral fat. ${ }^{27}$ There is strong evidence from prospective studies that the risk of type 2 diabetes increases progressively from a BMI of over $20 \mathrm{~kg} / \mathrm{m}^{2}$ after adjustment for age, family history of diabetes, physical activity, and smoking. ${ }^{28-30}$ Data from the DECODE-DECODA studies ${ }^{31}$ show a variation of risk for type 2 diabetes: the prevalence rising at BMI between 15-20 kg/m $\mathrm{m}^{2}$ among South Asians when compared with $15-20 \mathrm{~kg} / \mathrm{m}^{2}$ in Europeans.

Obesity occurs more frequently in black than white populations in the USA and there are ethnic differences in its expression even at young age. Among school children in Birmingham, Alabama the prevalence of obesity was $21 \%$ in white boys and girls compared with $26 \%$ in black boys and $38 \%$ in black girls. ${ }^{32}$ Furthermore, with African origin populations, for given levels of BMI, proportions of body fat rise considerably from Nigeria to Jamaica and US African Americans. ${ }^{33}$ Ethnic differences in lifestyle and economic factors may account for some of the ethnic disparities in obesity related diseases and disease outcomes.

\section{Dyslipidaemia}

Dyslipidaemia is common in people with type 2 diabetes, particularly those with poor glycaemic control. ${ }^{34}$ The increased synthesis of plasma lipoproteins and total cholesterol during hyperglycaemia contributes to the acceleration of atherosclerosis seen in type 2 diabetes. ${ }^{35}$ Augmented lipoprotein oxidation and glycation has been seen in diabetes, ${ }^{36} 37$ both of which affect the structure and function of endothelial cells. ${ }^{37}$ Among Pima Indians, independent of obesity, people who had normal glucose tolerance have been found to have significantly lower concentrations of total cholesterol, triglycerides, LDL-cholesterol, and increased high density lipoprotein (HDL) concentrations. However, with worsening glucose intolerance all these parameters dramatically deteriorate signifying the relation of dysglycaemia with dyslipidaemia. These changes in lipid related cardiovascular risk factors, as a consequence of diabetes, seem to result in worsened clinical outcomes. $^{38}$

\section{Hypertension}

Rising blood pressure confers a steep log-linear increase in cardiovascular events across its entire recorded range. ${ }^{39}$ Within the African Caribbean population there is a high incidence and prevalence of hypertension, in people with and without diabetes. ${ }^{40}{ }^{41}$ The situation worsens in all ethnic groups during the course of all types of diabetes, particularly when nephropathy ensues. ${ }^{42}$

\section{Gout}

Hyperuricaemia and gout commonly occur in type 2 diabetes. Gout is very common in Pacific Islanders such as the Maori of New Zealand ${ }^{43}$ who have a high prevalence of obesity. In USA, gout is more common in black than in white Americans. ${ }^{44}$ Although the prevalence has been low in SubSaharan Africa, current studies show mounting prevalence of gout in these areas. ${ }^{45}$ 
Table 2 Age and sex standardised prevalence rates (per 100) of type 2 diabetes and other conditions according to ethnic group $^{15}$

\begin{tabular}{|c|c|c|c|c|c|c|c|}
\hline & White & $\begin{array}{l}\text { All ethnic } \\
\text { minorities }\end{array}$ & African Caribbean & All South Asians & $\begin{array}{l}\text { Indian or } \\
\text { African Asian }\end{array}$ & $\begin{array}{l}\text { Pakistani or } \\
\text { Bangladeshi }\end{array}$ & Chinese \\
\hline Diabetes & 1.7 & 5.7 & 5.3 & 6.2 & 4.7 & 8.9 & 3 \\
\hline Hypertension & 12 & 11 & 17 & 9 & 8 & 11 & 5 \\
\hline CHD & 4.2 & 4 & 3.7 & 4.2 & 3.3 & 6 & 3 \\
\hline
\end{tabular}

CHD, coronary heart disease. Adapted with permission from Health Inequalities Life Course Approaches edited by George Davey Smith, 2003.

The insulin-like growth factor (IGF) system in relation to diabetes in different ethnic groups Insulin-like growth factor 1 (IGFI) plays an important part in glucose metabolism and homoeostasis. IGF bioactivity, unlike that of insulin, is modulated by a series of specific high affinity binding proteins (IGFBPs). Of the six IGFBPs fully characterised, IGF binding protein 1 (IGFBPI) is considered to be the principal hour to hour regulator of circulating IGF activity. ${ }^{46}$ In population studies, low circulating concentrations of IGFBPI are associated with insulin resistance ${ }^{47}$ and is significantly lower in people with impaired, when compared with normal, glucose tolerance in both Pakistani and European men and women ${ }^{48}$ (fig 1). In the UK Ely study the combination of low IGFI and IGFBPI predicted worsening glucose tolerance and diabetes at five year follow up $^{49}$ while low circulating IGFII concentrations were strongly associated with increased risk of gaining weight among men and women with normal glucose tolerance. ${ }^{50}$

Within people living in the UK, there is evidence of significant variation in IGF/IGFBP levels by ethnic group. IGFI levels have been found to be highest in normoglycaemic AfricanCaribbeans compared with Pakistani and Europeans in the UK, ${ }^{51}$ whereas IGFII concentrations were greatest in Europeans as were IGFBP3 levels in non-obese white European compared with Asian subjects. ${ }^{52}$ African-Caribbeans had the lowest mean IGFBPI concentrations among those with normal glucose tolerance. There was evidence for a dietary contribution to interethnic differences, ${ }^{53}$ although the effects of ethnicity independent of nutrition on circulating IGF concentrations remained dominant.

The variation in IGFI and IGFII by ethnic group is not accounted for by differences in other metabolic or anthropometric variables. What determines this ethnic variation remains to be clarified. However, the IGFs and their binding proteins may be more closely and consistently linked to the causal pathway of diabetic disease than the inconsistent results have been suggested for insulin.

\section{CHRONIC DIABETIC COMPLICATIONS AND ETHNICITY}

A UK cohort study over 20 year follow $u^{54}$ showed that prevalence of microvascular and macrovascular complications was lower in African-Caribbeans than in Europeans. African-Caribbeans with type 2 diabetes maintained a low risk of heart disease. ${ }^{54}$ Another study from the UK found no ethnic difference in diabetes related amputation in women. In men, the amputation risk in African-Caribbeans was one third that of Europeans. ${ }^{55}$

\section{ETHNIC DIFFERENCES IN THE MANAGEMENT OF DIABETES}

The treatment of type 1 diabetes is the same in all ethnic groups. In the USA, analysis of the NHANES survey data ${ }^{56}$ shows differences in the treatment of type 2 diabetes by ethnic group. A higher proportion of non-Hispanic black people were treated with insulin and a higher proportion of Mexican Americans were treated with oral agents compared with non-Hispanic white people. Most adults in each ethnic group (71\%-83\%) used pharmacological treatment for type 2 diabetes. Use of multiple daily insulin injections was more common in white people. Blood glucose self monitoring was less common in Mexican Americans, but most patients had never self monitored. Poor glycaemic control (HbAlc $>8 \%)$ was more common in non-Hispanic black women $(50 \%)$ and Mexican-American men (45\%) compared with the other groups $(35 \%-38 \%)$. There was no relation of glycaemic control to socioeconomic status or access to medical care in any ethnic group.

In the UKPDS, during the nine year follow up, body weight increased more in white patients (mean $5.0 \mathrm{~kg}$ ) than in African-Caribbean (3.0 kg) and Indian Asian (2.5 kg) patients. After adjusting for age, sex, baseline characteristics, treatment allocation, and change in weight, there were no consistent ethnic differences in mean change in fasting

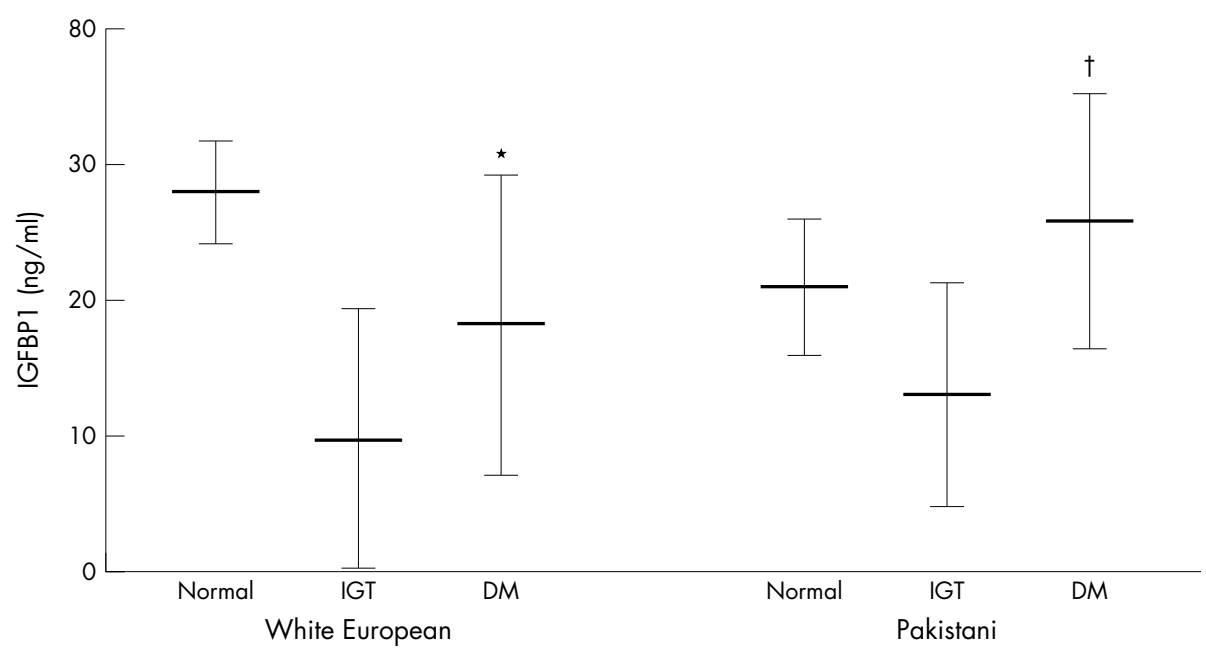

Figure 1 Fasting IGFBPI by GTT status for each ethnic group. *Europeans $F=6.7, p=0.002$ for comparison by GTT status, +Pakistanis $F=4.4, p=0.01$ for comparison by GTT status. The bars display the arithmetic means and $95 \%$ confidence limits. (Reproduced with permission from Heald et al. ${ }^{48}$ ) 
plasma glucose or HbAlc. After adjustment for antihypertensive therapy, increase in systolic blood pressure at nine years was greatest in African-Caribbean patients $(7 \mathrm{~mm} \mathrm{Hg}$ ). Mean diastolic blood pressure, total cholesterol, and LDL cholesterol decreased progressively during the nine years in each group. In African-Caribbean patients, the mean increase in HDL cholesterol $(0.16 \mathrm{mmol} / \mathrm{l})$ at three years, maintained to nine years, and the mean decrease in plasma triglyceride level $(0.4 \mathrm{mmol} / \mathrm{l})$ at nine years were greater than in white and Indian Asian patients. ${ }^{57}$ Clearly, African-Caribbean patients maintained the most favourable lipid profiles, but hypertension developed in more African-Caribbean patients than white or Indian Asian patients. These data show that in a clinical trial, African-Caribbeans did just as well or better than other groups, even if their community burden of the disease is high. Thus, contentiously for blood pressure, ${ }^{58}$ high prevalence need not be associated with poorer outcomes. So, it can be inferred that ethnicity specific glycaemic control of type 2 diabetes seems unnecessary, but other risk factors need to be managed independently.

\section{DIABETES MORTALITY IN DIFFERENT ETHNIC GROUPS}

Coronary heart disease mortality based on data from the England and Wales census 1991 is high in all ethnic groups. Coronary heart disease rates are particularly high in men and women born on the Indian sub-continent now living in the UK. Coronary heart disease is lower among people born in the Caribbean although type 2 diabetes is high in this group.

A UK study conducted among people with type 2 diabetes reported that mortality from heart disease was three times higher in South Asians, while mortality from stroke was 3.5-4 times higher in African-Caribbeans than in those born in England and Wales. ${ }^{59}$ This ethnic difference was greatest in the younger age group. Despite higher mortality from stroke, mortality from ischaemic heart disease was lower AfricanCaribbean men. Thus the high risk of heart disease should be targeted for intervention in South Asians, and the stroke targeted in African-Caribbeans. Managing global CHD risk aggressively, rather than specific risk factors on their own, has to be the main focus of modern treatment.

\section{Influence of socioeconomic position in ethnic groups and diabetes mortality}

Data from the fourth national survey of ethnic minorities ${ }^{15}$ show that except in African-Caribbean populations, age and sex standardised mortality for diabetes was higher in manual workers than in non-manual workers. In households in which there was no full time worker it was highest of all. The increased risk of diabetes in ethnic minority groups was found to be largely independent of current socioeconomic position. When controlled for age and sex, tenure or standard of living, the relative risk of diabetes remained largely unchanged. ${ }^{15}$

\section{ACCESS TO HEALTH CARE AND ETHNICITY}

GP consultations were found to be higher in Pakistani, Indian, and African-Caribbean adults compared with the general population ${ }^{60}$ but no account was taken of differences in morbidity. Barriers to care include poor understanding of the severity of symptoms, poor communication, knowledge of the value of preventative care, knowledge about the availability of services. South Asians have been found to be less likely to be given follow up GP appointments, ${ }^{61}$ to be offered district nurse services, ${ }^{62}$ and have had previous cardiological consultation. ${ }^{63}$

\section{PREVENTION OF DIABETES AND ETHNICITY}

Several trials have shown that reducing the progression to type 2 diabetes in high risk groups is possible and practical.
They have been undertaken in various countries and irrespective of ethnicity have shown positive results. Lifestyle interventions have more favourable results than drug interventions alone.

\section{Lifestyle}

The Da Qing study in China, ${ }^{64}$ the Finnish diabetes prevention study (FDPS), ${ }^{65}$ and the American diabetes prevention programme $(\mathrm{DPP})^{66}$ all showed that the prevention of diabetes is feasible through diet and exercise interventions in people with IGT. In the FDPS and DPP, the results were identical, a $58 \%$ reduction in the incidence of diabetes. ${ }^{65} 68$ Weight loss was central in both studies. The DPP included ethnic minorities although no separate analysis was done by ethnicity.

\section{Drugs}

A variety of drugs have been tried to prevent progression to diabetes. The Malmo study used tolbutamide and showed a decreased but not statistically significant progression to diabetes (29\% control compared with 13\% diet compared with $0 \%$ diet and tolbutamide). ${ }^{67}$ Metformin in the DPP showed a 31\% decrease in diabetes compared with 58\% reduction in the diet and exercise group. ${ }^{66}$ Acarbose, in the STOP-NIDDM trial, was claimed to reduce the risk of progression to diabetes by $25 \%$ with $0.5 \mathrm{~kg}$ weight loss irrespective of age, sex, and $\mathrm{BMI}^{68}$ although the validity of its analysis has been questioned. ${ }^{69}$ The TRIPOD study used thialzolidinediones in Hispanic women with history of gestational diabetes ${ }^{70}$ and reported $56 \%$ reduction in the progression to diabetes. In the Xendos study ${ }^{71}$ patients taking orlistat were $37 \%$ less likely to develop diabetes.

In view of the higher prevalence of diabetes in certain ethnic minorities in the UK, there is an urgent need to replicate these studies using culturally specific interventions.

\section{CONCLUSION}

Diabetes mellitus is a heterogeneous disease, characterised by metabolic disorders manifesting as relative or absolute deficiency of insulin. These conditions lead to cardiovascular, cerebral, and renal vascular disease, primarily through other risk factors, mainly high blood pressure, dyslipidaemia, and inflammation. While ethnicity has clear effects on the prevalence and incidence, aggressive management of these risk factors produces important benefits in all ethnic groups. The origin of the ethnic differences in incidence remains unclear but does not seem to be clearly genetic: intergenerational social factors seem to modulate the biology of the disease and its evolution and these should be amenable to treatment and prevention in all ethnic groups worldwide.

\section{Authors' affiliations}

J Oldroyd, M Banerjee, K Cruickshank, Clinical Epidemiology Group, University Department of Medicine, Manchester Royal Infirmary, Manchester, UK

A Heald, Department of Diabetes, Hope Hospital, Salford, UK

Funding: none.

Competing interests: none declared.

Ethical approval: none required.

\section{REFERENCES}

1 Wild S, Roglic G, Green A, et al. Global prevalence of diabetes: estimates for the year 2000 and projections for 2030. Diabetes Care 2004;27:1047-53.

2 Rangasami JJ, Greenwood DC, McSporran B, et al. Rising incidence of type 1 diabetes in Scottish children, 1984-93. The Scottish Study Group for the Care of Young Diabetics. Arch Dis Child 1997;77:210-13.

3 Glaser NS. Non-insulin-dependent diabetes mellitus in childhood and adolescence. Pediatr Clin North Am 1997;44:307-37. 
4 Li XH, Li TL, Yang Z, et al. A nine-year prospective study on the incidence of childhood type 1 diabetes mellitus in China. Biomed Environ Sci 2000;13:263-70.

5 Elamin A, Omer MI, Zein K, et al. Epidemiology of childhood type I diabetes in Sudan, 1987-1990. Diabetes Care 1992:15:1556-9.

6 Baker JR Jr. Autoimmune endocrine disease. JAMA 1997;278:1931-7.

7 Amos AF, McCarty DJ, Zimmet P. The rising global burden of diabetes and its complications: estimates and projections to the year 2010. Diabet Med 1997; 14(suppl 5):S1-85

8 Riste L, Khan F, Cruickshank K. High prevalence of type 2 diabetes in all ethnic groups, including Europeans, in a British inner city: relative poverty, history, inactivity, or 21 st century Europe? Diabetes Care 2001;24:1377-83.

9 Singh R, Shaw J, Zimmet P. Epidemiology of childhood type 2 diabetes in the developing world. Pediatr Diabetes 2004;5:154-68.

10 Wiegand S, Maikowski U, Blankenstein O, et al. Type 2 diabetes and impaired glucose tolerance in European children and adolescents with obesity - a problem that is no longer restricted to minority groups. Eur J Endocrinol 2004;151:199-206.

11 Zimmet PZ, McCarty DJ, de Court. The global epidemiology of non-insulindependent diabetes mellitus and the metabolic syndrome. J Diabetes Complications 1997;11:60-8.

12 Story M, Stevens J, Himes J, et al. Obesity in American-Indian children prevalence, consequences, and prevention. Prev Med 2003:37:S3-12.

13 Ehtisham S, Hattersley AT, Dunger DB, et al. First UK survey of paediatric type 2 diabetes and MODY. Arch Dis Child 2004;89:526-9.

14 Stride A, Hattersley AT. Different genes, different diabetes: lessons from maturity-onset diabetes of the young. Ann Med 2002;34:207-16.

15 Nazroo JY. The health of Britian's ethnic minorities: findings from a national survey. London: Policy Studies Institute, 1997.

16 Bhopal R, Unwin N, White M, et al. Heterogeneity of coronary heart disease risk factors in Indian, Pakistani, Bangladeshi, and European origin populations: cross sectional study. BMJ 1999;319:215-20.

17 Simmons D, Williams DR, Powell MJ. Prevalence of diabetes in different regional and religious south Asian communities in Coventry. Diabet Med 1992;9:428-31.

18 Abraham R, Brown MC, North WR, et al. Diets of Asian pregnant women in Harrow: iron and vitamins. Hum Nutr Appl Nutr 1987;41:164-73.

19 Hayes $L$, White $M$, Unwin $N$, et al. Patterns of physical activity and relationship with risk markers for cardiovascular disease and diabetes in Indian, Pakistani, Bangladeshi and European adults in a UK population. $J$ Public Health Med 2002;24:170-8.

20 Whincup PH, Gilg JA, Papacosta O, et al. Early evidence of ethnic differences in cardiovascular risk: cross sectional comparison of British South Asian and white children. BMJ 2002;324:635

21 Eriksson JG, Forsen T, Tuomilehto J, et al. Effects of size at birth and childhood growth on the insulin resistance syndrome in elderly individuals. Diabetologia 2002:45:342-8

22 Barker DJ, Hales CN, Fall CH, et al. Type 2 (non-insulin-dependent) diabetes mellitus, hypertension and hyperlipidaemia (syndrome $\mathrm{X}$ ): relation to reduced fetal growth. Diabetologia 1993;36:62-7

23 Fuller KE. Low birth-weight infants: the continuing ethnic disparity and the interaction of biology and environment. Ethn Dis 2000;10:432-45.

24 Gopalan C. Current food and nutrition situation in south Asian and south-east Asian countries. Biomed Environ Sci 1996;9:102-16.

25 Yajnik CS, Lubree HG, Rege SS, et al. Adiposity and hyperinsulinemia in Indians are present at birth. J Clin Endocrinol Metab 2002;87:5575-80.

26 Must A, Strauss RS. Risks and consequences of childhood and adolescent obesity. Int J Obes Relat Metab Disord 1999;23(suppl 2):S2-11.

27 Lonnqvist F, Thorne A, Large V, et al. Sex differences in visceral fat lipolysis and metabolic complications of obesity. Arterioscler Thromb Vasc Biol 1997; 17:1472-80.

28 Chan JM, Rimm EB, Colditz GA, et al. Obesity, fat distribution, and weight gain as risk factors for clinical diabetes in men. Diabetes Care 1994;17:961-9.

29 Shaper AG, Wannamethee SG, Walker M. Body weight: implications for the prevention of coronary heart disease, stroke, and diabetes mellitus in a cohort study of middle aged men. BMJ 1997;314:1311-17.

30 Colditz GA, Willett WC, Stampfer MJ, et al. Weight as a risk factor for clinical diabetes in women. Am J Epidemiol 1990;132:501-13.

31 Nakagami T, Qiao Q, Carstensen B, et al. Age, body mass index and type 2 diabetes-associations modified by ethnicity. Diabetologia 2003:46:1063-70.

32 Goran MI, Gower BA. Relation between visceral fat and disease risk in children and adolescents. Am J Clin Nutr 1999;70:149-56S.

33 Luke A, Durazo-Arvizu R, Rotimi C, et al. Relation between body mass index and body fat in black population samples from Nigeria, Jamaica, and the United States. Am J Epidemiol 1997;145:620-8.

34 Ramirez LC, Arauz-Pacheco C, Lackner C, et al. Lipoprotein (a) levels in diabetes mellitus: relationship to metabolic control. Ann Intern Med 1992;117:42-7.

35 Bennion L, Grundy SM. Effects of diabetes mellitus on cholesterol metabolism in man. N Engl J Med 1977;296:1365-71.

36 Bucala R, Makita Z, Koschinsky T, et al. Lipid advanced glycosylation: pathway for lipid oxidation in vivo. Proc Natl Acad Sci U S A 1993:90:6434-8.

37 Lyons TJ. Glycation and oxidation: a role in the pathogenesis of atherosclerosis. Am J Cardiol 1993;71:26-31B.

38 Harris SB, Zinman B, Hanley A, et al. The impact of diabetes on cardiovascular risk factors and outcomes in a native Canadian population. Diabetes Res Clin Pract 2002;55:165-73.

39 Collins R, Peto R, Godwin J, et al. Blood pressure and coronary heart disease. Lancet 1990;336:370-1.
40 Saunders E. Hypertension in blacks. Med Clin North Am 1987:71:1013-29.

41 Li S, McAlpine DD, Liu J, et al. Differences between blacks and whites in the incidence of end-stage renal disease and associated risk factors. Adv Ren Replace Ther 2004;11:5-13.

42 Corry D, Tuck M. Hypertension and diabetes. Semin Nephrol $1991 ; 11: 561-70$

43 Gibson $T$, Waterworth R, Hatfield $\mathrm{P}$, et al. Hyperuricaemia, gout and kidney function in New Zealand Maori men. Br J Rheumatol 1984;23:276-82.

44 Hochberg MC, Thomas J, Thomas DJ, et al. Racial differences in the incidence of gout. The role of hypertension. Arthritis Rheum 1995;38:628-32.

45 Tikly M, Bellingan A, Lincoln D, et al. Risk factors for gout: a hospital-based study in urban black South Africans. Rev Rhum Engl Ed 1998;65:225-31.

46 Lee PD, Giudice LC, Conover CA, et al. Insulin-like growth factor binding protein-1: recent findings and new directions. Proc Soc Exp Biol Med 1997;216:319-57.

47 Janssen JA, Stolk RP, Pols HA, et al. Serum free and total insulin-like growth factor-I, insulin-like growth factor binding protein-1 and insulin-like growth factor binding protein-3 levels in healthy elderly individuals. Relation to selfreported quality of health and disability. Gerontology 1998;44:277-80.

48 Heald AH, Cruickshank JK, Riste LK, et al. Close relation of fasting insulin-like growth factor binding protein-1 (IGFBP-1) with glucose tolerance and cardiovascular risk in two populations. Diabetologia 2001;44:333-9.

49 Sandhu MS, Heald AH, Gibson JM, et al. Circulating concentrations of insulinlike growth factor-I and development of glucose intolerance: a prospective observational study. Lancet 2002;359:1740-5.

50 Sandhu MS, Gibson JM, Heald AH, et al. Low circulating IGF-II concentrations predict weight gain and obesity in humans. Diabetes 2003:52:1403-8.

51 Cruickshank JK, Heald AH, Anderson S, et al. Epidemiology of the insulin-like growth factor system in three ethnic groups. Am J Epidemiol $2001 ; 154: 504-13$.

52 Hopkins KD, Lehmann ED, Jones RL, et al. Ethnicity affects IGFBP-3 and IGF-II in normal healthy young adult subjects. Clin Endocrinol (Oxf) 1996;45:327-31

53 Heald AH, Cade JE, Cruickshank JK, et al. The influence of dietary intake on the insulin-like growth factor (IGF) system across three ethnic groups: a population-based study. Public Health Nutr 2003;6:175-80.

54 Chaturvedi N, Jarrett J, Morrish N, et al. Differences in mortality and morbidity in African Caribbean and European people with non-insulin dependent diabetes mellitus: results of 20 year follow up of a London cohort of a multinational study. BMJ 1996;313:848-52.

55 Leggetter S, Chaturvedi N, Fuller $\mathrm{JH}$, et al. Ethnicity and risk of diabetesrelated lower extremity amputation: a population-based, case-control study of African Caribbeans and Europeans in the United kingdom. Arch Intern Med 2002;162:73-8.

56 Harris MI, Eastman RC, Cowie CC, et al. Racial and ethnic differences in glycemic control of adults with type 2 diabetes. Diabetes Care 1999;22:403-8.

57 UK Prospective Diabetes Study (UKPDS) Group. Effect of intensive bloodglucose control with metformin on complications in overweight patients with type 2 diabetes (UKPDS 34). Lancet 1998;352:854-65.

58 Cruickshank JK, Alleyne SA. Black West Indian and matched white diabetics in Britain compared with diabetics in Jamaica: body mass, blood pressure, and vascular disease. Diabetes Care 1987;10:170-9.

59 Chaturvedi N, Fuller JH. Ethnic differences in mortality from cardiovascular disease in the UK: do they persist in people with diabetes? J Epidemiol Community Health 1996;50:137-9.

60 Balarajan R, Yuen P, Soni RV. Ethnic differences in general practitioner consultations. BMJ 1989;299:958-60.

61 Gillam SJ, Jarman B, White P, et al. Ethnic differences in consultation rates in urban general practice. BMJ 1989;299:953-9.

62 Badger F, Atkin K, Griffiths R. Why don't general practitioners refer their disabled Asian patients to district nurses? Health Trends 1989:21:31-2.

63 Shaukat N, de Bono DP, Cruickshank JK. Clinical features, risk factors, and referral delay in British patients of Indian and European origin with angina matched for age and extent of coronary atheroma. BMJ 1993;307:717-18

64 Pan XR, Li GW, Hu YH, et al. Effects of diet and exercise in preventing NIDDM in people with impaired glucose tolerance. The Da Qing IGT and diabetes study. Diabetes Care 1997;20:537-44.

65 Tuomilehto J, Lindstrom J, Eriksson JG, et al. Prevention of type 2 diabetes mellitus by changes in lifestyle among subjects with impaired glucose tolerance. N Engl J Med 2001;344:1343-50.

66 Knowler WC, Barrett-Connor E, Fowler SE, et al. Reduction in the incidence of type 2 diabetes with lifestyle intervention or metformin. N Engl J Med 2002; 346:393-403

67 Sartor G, Schersten B, Carlstrom S, et al. Ten-year follow-up of subjects with impaired glucose tolerance: prevention of diabetes by tolbutamide and diet regulation. Diabetes 1980;29:41-9.

68 Chiasson JL, Josse RG, Gomis R, et al. Acarbose for prevention of type 2 diabetes mellitus: the STOP-NIDDM randomised trial. Lancet 2002;359:2072-7.

69 Kaiser T, Sawicki PT. Acarbose for prevention of diabetes, hypertension and cardiovascular events? A critical analysis of the STOP-NIDDM data. Diabetologia 2004;47:575-80.

70 Buchanan TA, Xiang AH, Peters RK, et al. Preservation of pancreatic beta-cell function and prevention of type 2 diabetes by pharmacological treatment of insulin resistance in high-risk hispanic women. Diabetes 2002;51:2796-803

71 Torgerson JS, Hauptman J, Boldrin MN, et al. XENical in the prevention of diabetes in obese subjects (XENDOS) study: a randomized study of orlistat as an adjunct to lifestyle changes for the prevention of type 2 diabetes in obese patients. Diabetes Care 2004;27:155-61. 